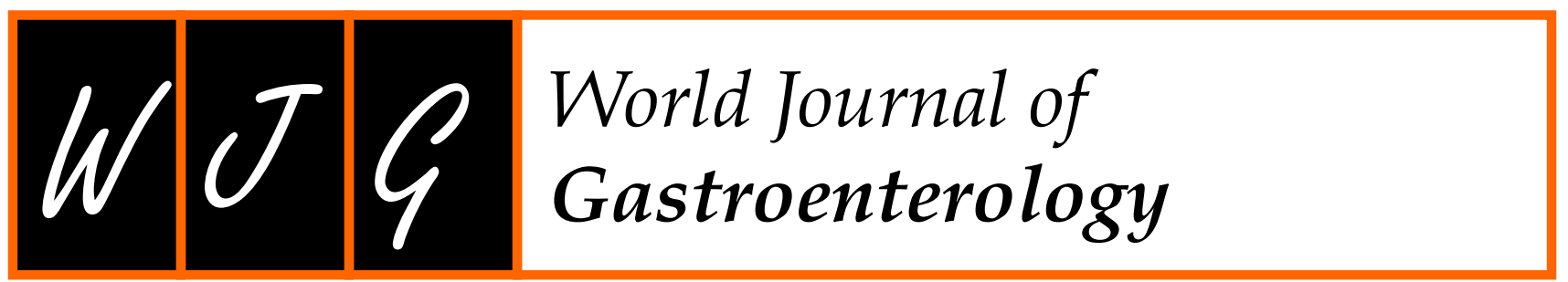

\title{
Body-mass index correlates with severity and mortality in acute pancreatitis: A meta-analysis
}

Dalma Dobszai, Péter Mátrai, Zoltán Gyöngyi, Dezső Csupor, Judit Bajor, Bálint Erőss, Alexandra Mikó, Lajos Szakó, Ágnes Meczker, Roland Hágendorn, Katalin Márta, Andrea Szentesi, Péter Hegyi, on behalf of the Hungarian Pancreatic Study Group

\section{ORCID number: Dalma Dobszai (0000-0002-8703-1381); Péter Mátrai (0000-0001-5144-0733); Zoltán Gyöngyi (0000-0001-9330-9119); Dezső Csupor \\ (0000-0002-4088-3333); Judit Bajor (0000-0002-3941-4871); Bálint Erőss (0000-0003-3658-8427); Alexandra Mikó (0000-0002-5322-4425); Lajos Szakó (0000-0001-9783-4076); Ágnes Meczker (0000-0002-2646-2217); Roland Hágendorn \\ (0000-0002-9984-2309); Katalin Márta (0000-0002-2213-4865); \\ Andrea Szentesi \\ (0000-0003-2097-6927); Péter Hegyi (0000-0003-0399-7259).}

Author contributions: Dobszai D, Bajor J, Hágendorn R and Szakó L conducted the search in the databases. Mikó A, Meczker Á, Márta $\mathrm{K}$ and Csupor D read the articles for eligibility; in the case of conflict, the decision was left to a third participant, Hegyi P. Dobszai D, Meczker Á and Mikó A entered the data from the articles in an Excel file, while Mátrai $P$ analyzed the data. Dobszai D and Gyöngyi Z carried out the bias analysis.

Dobszai D, Mikó A and Márta K drafted the manuscript, and Szentesi A, Hágendorn R and Bajor J edited it. Meczker Á and Szentesi A edited the tables and figures. Dobszai D, Bajor J and Szakó L completed the items on the PRISMA-recommended checklist. Hegyi $\mathrm{P}$ and Erőss B made a critical revision of the finalized manuscript. All the authors read and approved the final manuscript.

Supported by a Project Grant (No.
Dalma Dobszai, Péter Mátrai, Bálint Erőss, Alexandra Mikó, Lajos Szakó, Ágnes Meczker, Katalin Márta, Andrea Szentesi, Péter Hegyi, Institute for Translational Medicine, Medical School, University of Pécs, Pécs 7624, Hungary

Dalma Dobszai, Andrea Szentesi, Clinical Medicine Doctoral School, University of Szeged, Szeged 6720, Hungary

Péter Mátrai, Institute for Bioanalysis, Medical School, University of Pécs, Pécs 7624, Hungary

Zoltán Gyöngyi, Department of Public Health Medicine, Medical School, University of Pécs, Pécs 7624, Hungary

Dezső Csupor, Department of Pharmacognosy, University of Szeged, Szeged 6720, Hungary

Judit Bajor, Roland Hágendorn, Division of Gastroenterology, First Department of Medicine, University of Pécs, Medical School, Pécs 7624, Hungary

Katalin Márta, János Szentágothai Research Center, University of Pécs, Pécs 7624 Hungary

Péter Hegyi, MTA-SZTE Momentum Translational Gastroenterology Research Group, University of Szeged, Szeged 6720, Hungary

Corresponding author: Péter Hegyi, MD, PhD, DSc, Professor of Medicine, Director, Institute for Translational Medicine, Medical School, University of Pécs, 12 Szigeti Street, Pécs H7624, Hungary. hegyi2009@gmail.com

Telephone: +36-70-3751031

\section{Abstract}

\section{BACKGROUND}

Obesity rates have increased sharply in recent decades. As there is a growing number of cases in which acute pancreatitis (AP) is accompanied by obesity, we found it clinically relevant to investigate how body-mass index (BMI) affects the outcome of the disease.

\section{AIM}

To quantify the association between subgroups of BMI and the severity and mortality of AP.

\section{METHODS}

A meta-analysis was performed using the Preferred Reporting Items for 
KH125678 to PH); an Economic Development and Innovation Operative Program Grant (GINOP 2.3.2-15-2016-00048 to PH; and a Human Resources Development Operational Program Grant (No. EFOP-3.6.2-16-2017-00006 to PH) from the National Research, Development and Innovation Office as well as by a Momentum Grant from the Hungarian Academy of Sciences (No. LP201410/2014 to PH); EFOP-3.6.3VEKOP-16-2017-00009 and UNKP18-3-INew National Excellence Program of the Ministry of Human Capacities (No. PTE/38329-1/2018 to KM).

Conflict-of-interest statement: The authors declare that no conflict of interest exists. There are no financial or other competing interests for principal investigators, patients included or any member of the trial.

PRISMA 2009 Checklist statement: The authors have read the PRISMA 2009 Checklist, and the manuscript was prepared and revised according to the PRISMA 2009 Checklist.

Open-Access: This article is an open-access article which was selected by an in-house editor and fully peer-reviewed by external reviewers. It is distributed in accordance with the Creative Commons Attribution Non Commercial (CC BY-NC 4.0) license, which permits others to distribute, remix, adapt, build upon this work non-commercially, and license their derivative works on different terms, provided the original work is properly cited and the use is non-commercial. See: http://creativecommons.org/licen ses/by-nc/4.0/

\section{Manuscript source: Unsolicited} manuscript

Received: November 7, 2018 Peer-review started: November 12 , 2018

First decision: November 22, 2018

Revised: December 4, 2018

Accepted: December 19, 2018

Article in press: December 20, 2018

Published online: February 14, 2019
Systematic Review and Meta-Analysis (PRISMA) Protocols. Three databases (PubMed, EMBASE and the Cochrane Library) were searched for articles containing data on BMI, disease severity and mortality rate for AP. Englishlanguage studies from inception to 19 June 2017 were checked against our predetermined eligibility criteria. The included articles reported all AP cases with no restriction on the etiology of the disease. Only studies that classified AP cases according to the Atlanta Criteria were involved in the severity analyses. Odds ratios (OR) and mean differences (MD) were pooled using the random effects model with the DerSimonian-Laird estimation and displayed on forest plots. The meta-analysis was registered in PROSPERO under number CRD42017077890.

\section{RESULTS}

A total of 19 articles were included in our meta-analysis containing data on 9997 patients. As regards severity, a subgroup analysis showed a direct association between AP severity and BMI. BMI < 18.5 had no significant effect on severity; however, BMI $>25$ had an almost three-fold increased risk for severe AP in comparison to normal BMI (OR $=2.87,95 \% \mathrm{CI}$ : $1.90-4.35, P<0$.001). Importantly, the mean BMI of patients with severe AP is higher than that of the non-severe group $(\mathrm{MD}=1.79,95 \% \mathrm{CI}$ : 0.89-2.70, $P<0.001)$. As regards mortality, death rates among AP patients are the highest in the underweight and obese subgroups. A $\mathrm{BMI}<18.5$ carries an almost two-fold increase in risk of mortality compared to normal BMI $(\mathrm{OR}=1.82,95 \% \mathrm{CI}: 1.32-2.50, P<0.001)$. However, the chance of mortality is almost equal in the normal BMI and BMI 25-30 subgroups. A BMI > 30 results in a three times higher risk of mortality in comparison to a BMI $<30$ $(\mathrm{OR}=2.89,95 \% \mathrm{CI}: 1.10-7.36, P=0.026)$.

\section{CONCLUSION}

Our findings confirm that a BMI above 25 increases the risk of severe AP, while a $\mathrm{BMI}>30$ raises the risk of mortality. A BMI $<18.5$ carries an almost two times higher risk of mortality in AP.

Key words: Acute pancreatitis; Body-mass index; Obesity; Severity; Mortality; Prognostic; Meta-analysis

CThe Author(s) 2019. Published by Baishideng Publishing Group Inc. All rights reserved.

Core tip: It is the first detailed analysis on all World Health Organization body-mass index (BMI) categories, by comparing the normal BMI subgroup to all other subgroups of BMI with regard to both severity and mortality in acute pancreatitis (AP). Here we show that a BMI above 25 increases the risk of severe AP, while a BMI $>30$ raises the risk of mortality. A BMI lower than eighteen point five carries an almost two times higher risk of mortality in AP.

Citation: Dobszai D, Mátrai P, Gyöngyi Z, Csupor D, Bajor J, Erőss B, Mikó A, Szakó L, Meczker Á, Hágendorn R, Márta K, Szentesi A, Hegyi P, on behalf of the Hungarian Pancreatic Study Group. Body-mass index correlates with severity and mortality in acute pancreatitis: A meta-analysis. World J Gastroenterol 2019; 25(6): 729-743

URL: https:/www.wjgnet.com/1007-9327/full/v25/i6/729.htm

DOI: https://dx.doi.org/10.3748/wjg.v25.i6.729

\section{INTRODUCTON}

Obesity is one of the dominant public health concerns worldwide. It is a major risk factor for various diseases such as diabetes, cardiovascular disease, some cancers, kidney disease, obstructive sleep apnea, gout, osteoarthritis, and hepatobiliary disease ${ }^{[1]}$. The increasing prevalence of obesity (Figures 1 and 2$)^{[2]}$ also places a huge financial burden on national healthcare systems: according to a review published in 2010 , obesity alone accounts for between $0.7 \%$ and $2.8 \%$ of total healthcare expenditures, while costs associated with a body-mass index $(\mathrm{BMI}) \geq 25$ reach as high as $9.1 \%$ of total spending on medical care ${ }^{[3]}$. 


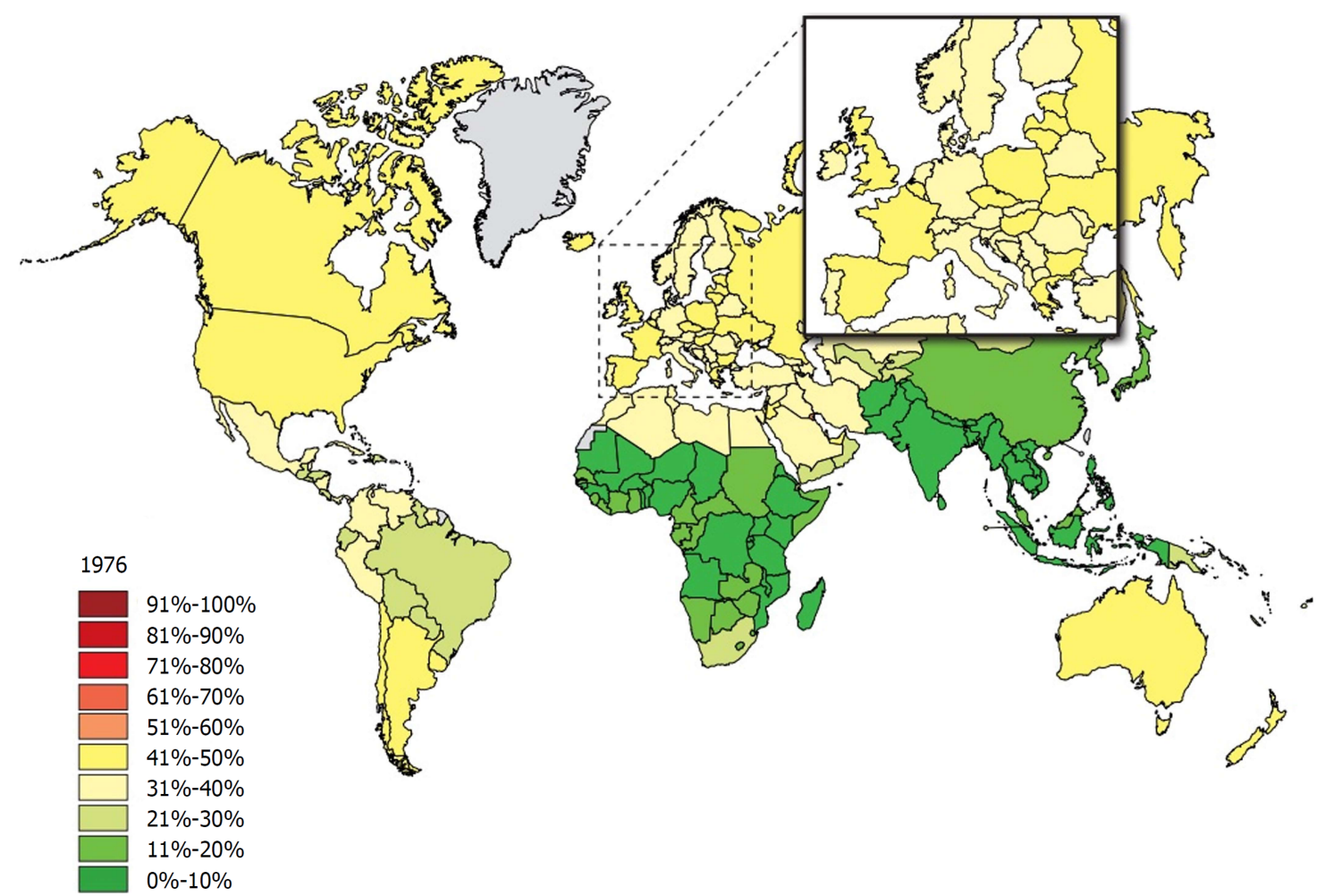

Figure 1 The rate of individuals with a body-mass index $\geq 25$ among adults in 1976. Source: Global Health Observatory data repository http://apps.who.int/gho/data/node.main.A897A?lang=en.

The most common method for measuring obesity is BMI, which is calculated from a person's weight in kilograms and height in meters $\left(\mathrm{kg} / \mathrm{m}^{2}\right)$. BMI is divided into five categories according to the World Health Organization (WHO) classification: underweight $\left(<18.5 \mathrm{~kg} / \mathrm{m}^{2}\right)$, normal weight $\left(18.5-24.9 \mathrm{~kg} / \mathrm{m}^{2}\right)$, overweight $(25-29.9$ $\left.\mathrm{kg} / \mathrm{m}^{2}\right)$, obese class I $\left(30-34.9 \mathrm{~kg} / \mathrm{m}^{2}\right)$, obese class II $\left(35-39.9 \mathrm{~kg} / \mathrm{m}^{2}\right)$ and obese class III $\left(\geq 40 \mathrm{~kg} / \mathrm{m}^{2}\right)^{[4]}$.

Among various other diseases, there is an increasing number of clinical cases in which acute pancreatitis (AP) is also accompanied by high BMI. Characterized by high mortality, AP is the most frequent cause of acute hospitalization among all gastrointestinal disorders with a prevalence of 10-100/100000 cases worldwide ${ }^{[5]}$. The B5 point of the IAP/APA evidence-based guidelines highlights the importance of predicting the primary endpoints of $\mathrm{AP}$, namely severity and mortality, therefore, we found it crucially important to investigate how obesity affects the outcome of the disease $^{[6]}$. Numerous studies have also linked severe acute pancreatitis (SAP) with obesity. The majority of the clinical trials conducted with the aim of determining the sensitivity and specificity of the predictive score systems of AP with the obesity factor added to it resulted in greater diagnostic accuracy ${ }^{[7-9]}$.

Despite the fact that there is evidence of high BMI exacerbating AP, there has been a lack of structured and completed analyses. Until now, four meta-analyses have been performed to investigate the prognostic role of $\mathrm{BMI}$ in $\mathrm{AP}$; however, none of them (1) analyzed all five WHO BMI categories, (2) compared the normal BMI group to every other subgroup, (3) investigated the effect of underweight on AP outcome or (4) suggested cut-off values ${ }^{[10-13]}$. The last meta-analysis on this topic was conducted in 2011, so our update involves new articles published during the last six years, leading to a remarkably higher patient number than before.

\section{MATERIALS AND METHODS}

\section{Literature search}

This meta-analysis was conducted following the guidelines proposed by the PRISMA Statement ${ }^{[14]}$. The protocol was previously registered on PROSPERO under CRD42017077890. A systematic search of the medical literature was performed using PubMed, EMBASE and the Cochrane Library. In all the databases, the following keywords were used for the search: acute pancreatitis AND BMI AND (severity OR 


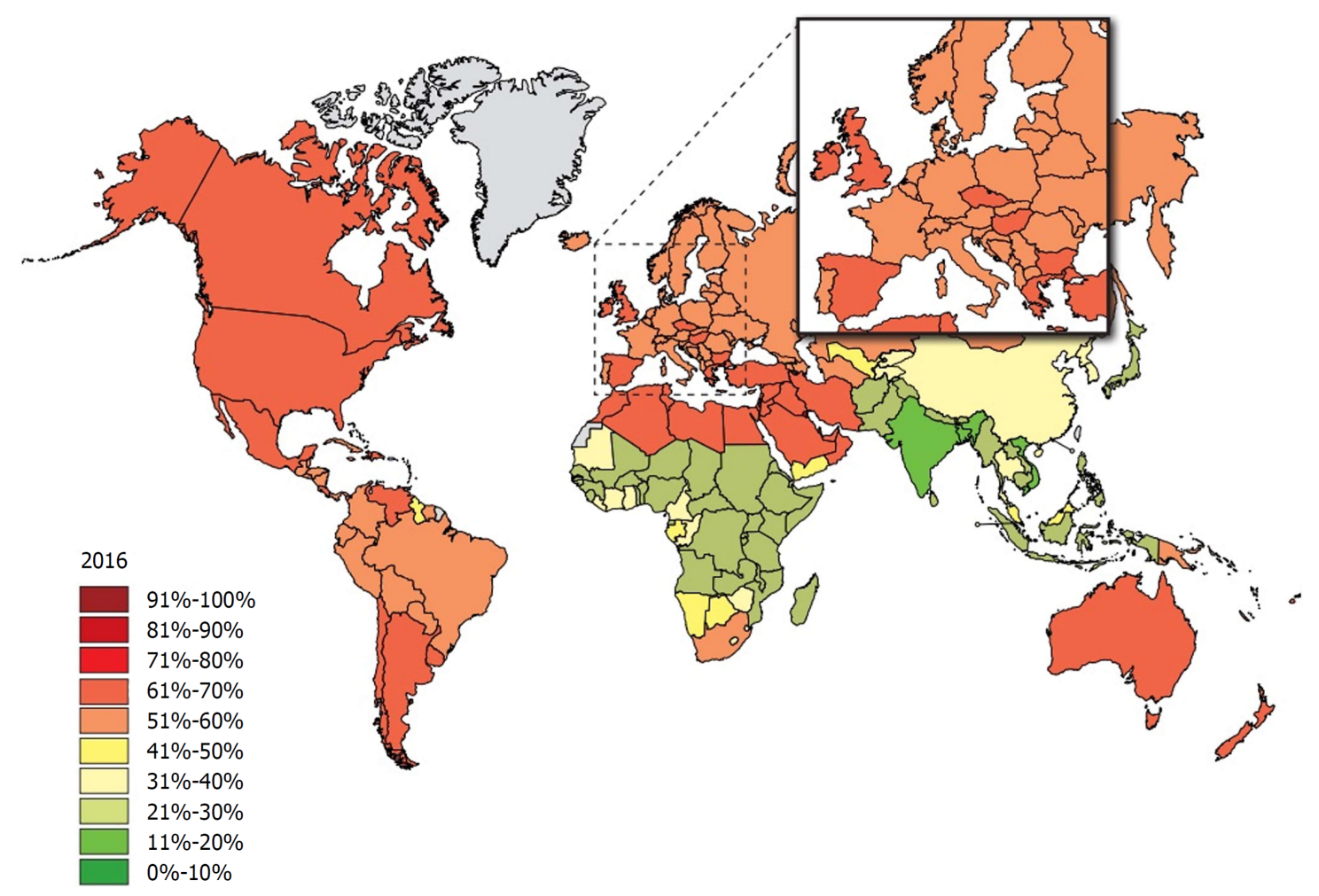

Figure 2 The rate of individuals with a body-mass index $\geq 25$ among adults 40 years later in 2016. Source: Global Health Observatory data repository (http://apps.who.int/gho/data/node.main.A897A?lang=en).

mortality). Results were imported into reference manager software (EndNote X7.5). The reference lists in the articles were also checked to capture all relevant articles published within our topic of interest. The last literature search in the same databases was completed on $22^{\text {nd }}$ December 2017. The details of these literature searches are included in the Supporting Material. We adapted the PICO format to set the inclusion criteria. Our PICO items were the following: (P) patients with AP, (I) low/high BMI, (C) normal BMI, and (O) severity and mortality of pancreatitis. Besides these two major endpoints of AP, we also collected data on the length of hospitalization and local or systemic complications for the purpose of analysis.

\section{Study selection}

Two of the authors independently checked whole texts with figures and tables against our predetermined eligibility criteria. During the selection process, meta-analyses, reviews, case reports and abstracts with inadequate data were excluded. Articles were declared eligible if the study enrolled all AP patients with no restriction on one specific etiology. In the severity analysis, we only included studies in which the original $^{[15]}$ or the revised ${ }^{[16]}$ version of the Atlanta Criteria were used to determine the severity of AP. However, in the analysis of the effect of BMI on mortality, the use of the Atlanta Classification was not a criterion.

\section{Data extraction}

Review authors entered the following main data from the eligible articles (Table 1 ) on an Excel sheet: (1) First author, year of publication, country; (2) Study type; (3) Group of enrolled patients; (4) BMI subgroups and sample sizes; (5) Method used to define disease severity; (6) Mean BMI; (7) Number of severe cases and mortality; (8) Mean length of hospitalization and mean Intensive Care Unit stay in days; (9) Mean or median severity scores: Acute Physiology and Chronic Health Disease Classification System II (APACHE II) and Ranson's score; and (10) Number of cases with necrosis development. Discrepancies were resolved by consensus.

\section{Risk of bias}

Risk of bias assessment was carried out according to a modified version of the Newcastle-Ottawa Scale (NOS) to rate the internal validity of the individual studies, and funnel plots were constructed to assess the risk of publication bias (Supporting Material). 
Table 1 Characteristics of the included studies

\begin{tabular}{|c|c|c|c|c|c|c|}
\hline Ref. & Country & Type of study & Total no. of patients & Groups & BMI groups & Sample size \\
\hline \multirow[t]{2}{*}{ Bota et al ${ }^{[32]}$} & Romania & Retrospective & 334 & Mild & & 207 \\
\hline & & & & Severe & & 127 \\
\hline \multirow[t]{2}{*}{ Duarte-Rojo et al ${ }^{[18]}$} & Mexico & Prospective & 99 & Mild & & 74 \\
\hline & & & & Severe & & 25 \\
\hline \multirow[t]{4}{*}{ Funnel et al ${ }^{[29]}$} & South Africa & Prospective & 99 & & $<19$ & 15 \\
\hline & & & & & $19-25$ & 48 \\
\hline & & & & & $26-29$ & 17 \\
\hline & & & & & $\geq 30$ & 19 \\
\hline \multirow[t]{2}{*}{ Karpavicius et al ${ }^{[23]}$} & Lithuania & Prospective & 102 & Mild and moderate & & 82 \\
\hline & & & & Severe & & 20 \\
\hline \multirow[t]{2}{*}{ Katuchova et al ${ }^{[21]}$} & Slovakia & Prospective & 384 & IEP & & 293 \\
\hline & & & & SAP & & 91 \\
\hline \multirow[t]{3}{*}{ Mery et al ${ }^{[25]}$} & Mexico & Prospective & 88 & & $<25$ & 34 \\
\hline & & & & & $25-29.9$ & 32 \\
\hline & & & & & $\geq 30$ & 22 \\
\hline \multirow[t]{2}{*}{ Papachristou et al ${ }^{[8]}$} & United States & Prospective & 102 & & $<30$ & 74 \\
\hline & & & & & $\geq 30$ & 28 \\
\hline \multirow[t]{6}{*}{ Párniczky et al ${ }^{[5]}$} & Hungary & Prospective, multicenter & 446 & & $<18.5$ & 26 \\
\hline & & & & & $18.5-24.9$ & 136 \\
\hline & & & & & $25-29.9$ & 154 \\
\hline & & & & & $30-34.9$ & 86 \\
\hline & & & & & 35-39.9 & 24 \\
\hline & & & & & $>40$ & 20 \\
\hline \multirow[t]{2}{*}{ Sharma et al ${ }^{[30]}$} & United States & Prospective & 128 & & $<30$ & 87 \\
\hline & & & & & $\geq 30$ & 41 \\
\hline \multirow[t]{4}{*}{ Shin et al ${ }^{[20]}$} & South Korea & Retrospective & 374 & & $18.5-22.9$ & 170 \\
\hline & & & & & 23-24.9 & 96 \\
\hline & & & & & $25-29.9$ & 97 \\
\hline & & & & & $\geq 30$ & 11 \\
\hline \multirow[t]{2}{*}{ Suazo-Barahona et al ${ }^{[26]}$} & Mexico & Retrospective & 150 & & $<25$ & 65 \\
\hline & & & & & $\geq 25$ & 85 \\
\hline \multirow[t]{5}{*}{ Taguchi et al ${ }^{[31]}$} & Japan & Retrospective & 6002 & & $<18.5$ & 839 \\
\hline & & & & & $18.5-24.9$ & 3767 \\
\hline & & & & & $25-29.9$ & 1106 \\
\hline & & & & & $30-34.9$ & 220 \\
\hline & & & & & $>35$ & 70 \\
\hline \multirow[t]{3}{*}{ Thandassery et al ${ }^{[27]}$} & India & Prospective & 280 & & $18.5-22.9$ & 131 \\
\hline & & & & & $23-24.9$ & 83 \\
\hline & & & & & $>25$ & 66 \\
\hline \multirow[t]{2}{*}{ Tsai et al ${ }^{[34]}$} & Taiwan & Prospective & 320 & & $<30$ & 294 \\
\hline & & & & & $\geq 30$ & 26 \\
\hline \multirow[t]{2}{*}{ Türkoglu et al ${ }^{[24]}$} & Turkey & Prospective cohort study & 92 & Mild & & 62 \\
\hline & & & & Severe & & 30 \\
\hline \multirow[t]{2}{*}{ Yang et al ${ }^{[28]}$} & China & Prospective, multicenter & 161 & & $\geq 25$ & 82 \\
\hline & & & & & $\geq 25$ & 79 \\
\hline \multirow[t]{2}{*}{ Yashima et al ${ }^{[22]}$} & Japan & Prospective & 124 & Mild & & 76 \\
\hline & & & & Severe & & 48 \\
\hline \multirow[t]{2}{*}{ Yeung et al ${ }^{[19]}$} & China & Prospective & 101 & & $<25$ & 19 \\
\hline & & & & & $\geq 25$ & 82 \\
\hline \multirow[t]{3}{*}{ Yoon et al ${ }^{[17]}$} & South Korea & Retrospective & 203 & Mild & & 128 \\
\hline & & & & Moderate & & 62 \\
\hline & & & & Severe & & 13 \\
\hline
\end{tabular}




\section{Statistical analysis}

The statistical analysis was conducted with Stata 11 SE (Stata Corp, College Station, TX, United States). First, we calculated mean differences from BMI in severe and nonsevere groups and odds ratios (OR) for severity and mortality outcomes based on patient numbers in different BMI categories. ORs and mean differences were pooled using the random effects model with the DerSimonian-Laird estimator and displayed on forest plots. Summary OR and mean estimation, $P$-value and $95 \%$ confidence interval $(\mathrm{CI})$ were calculated. $P<0.05$ was considered a significant difference from summary OR $=1$ or mean $=0$. Statistical heterogeneity was analyzed using the $I^{2}$ statistic and the chi-square test to obtain probability values; $P<0.05$ was determined to indicate significant heterogeneity. We investigated the possible signs of a small study effect, displaying the studies on a funnel plot with the trim and fill algorithm.

\section{RESULTS}

The systematic search of the literature yielded 262 items. After eliminating duplicates, 217 records were screened by title and abstract. 156 articles were included in the fulltext assessment, of which 15 studies met our predetermined eligibility criteria. An additional four articles included in the quantitative synthesis were found by checking the references of the originally identified articles (Figure 3).

The interpretation of cut-off values was not unified in the enrolled studies that investigated the effect of obesity in AP. As articles used different BMI grouping and not all articles contained data on all BMI subgroups, we decided to use several statistical approaches.

\section{Severity}

Nine articles ${ }^{[17-24,32]}$ presented data on the mean BMI of the non-severe and severe patient groups (Figure 4). This meta-analysis showed that severe AP patients have a significantly higher BMI compared to those with moderately severe and severe AP $(\mathrm{MD}=1.79,95 \% \mathrm{CI}: 0.89-2.70, P<0.001)$. AP patients with a BMI $>25$ are almost three times more likely to develop a severe disease than normal weight and underweight patients $(\mathrm{OR}=2.87,95 \% \mathrm{CI}$ : 1.90-4.35, $P<0.001)$ according to the analysis of data from eight additional studies ${ }^{[5,19-20,25-29]}$ (Figure 5). Data from five articles ${ }^{[5,20,25,29-30]}$ also made it possible to set a BMI of $30 \mathrm{~kg} / \mathrm{m}^{2}$ as a cut-off value in our severity analysis. There is a sharp difference between obese and non-obese patients in the chance for developing a severe disease: a patient with a BMI $>30$ has an almost four times higher odds of SAP than one with a BMI $<30(\mathrm{OR}=3.61,95 \% \mathrm{CI}: 1.56-8.36, P=0.003)$ (Figure 6).

Comparing the normal BMI group to every other BMI category $(<18.5 ; 25-30 ; 30-35$; $>35 \mathrm{~kg} / \mathrm{m}^{2}$ ) in a summary effect analysis (Figure 7) showed that overweight and obese patients are more likely to develop a severe disease than patients in all other BMI categories $(\mathrm{OR}=2.53,95 \% \mathrm{CI}: 1.64-3.90, P=0.000$ and $\mathrm{OR}=2.99,95 \% \mathrm{CI}: 1.13-7.92$, $P=0.028)$. Underweight compared to normal BMI also seems to increase the risk of severe $\mathrm{AP}(\mathrm{OR}=1.89,95 \% \mathrm{CI}$ : 0.52-6.87, $P=0.336)$; however, the differences are not significant. The reason behind the lack of significance may be the particularly low number of patients in the underweight subgroup $(n=184)$. Forming subgroups from each BMI category (underweight, normal weight, overweight and obese) confirmed the previously identified tendency: the higher the BMI, the higher the chance of developing severe AP (Figure 8).

\section{Mortality}

A total of ten ${ }^{[5,8,19-20,25-29,31]}$ of the 19 enrolled studies were included in this part of the meta-analysis. While a BMI > 25 represents a higher chance of developing severe AP, it does not significantly increase the mortality of the disease $(\mathrm{OR}=2.46,95 \% \mathrm{CI}$ : 0.78 $7.79, P=0.125$ ) (Figure 9). However, obese patients are at a three-fold increased risk of mortality compared to those with a BMI $<30$ (OR $=2.89,95 \% \mathrm{CI}: 1.14-7.36, P=0.026)$ (Figure 10). One with a BMI $<18.5$ is also at a significantly higher risk of mortality in AP than a normal weight patient $(\mathrm{OR}=1.82,95 \% \mathrm{CI}$ : 1.32-2.50, $P=0.000)$ (Figure 11). Death rates among AP patients are the highest in the underweight and obese subgroups (Figures 12 and 13), while the chance of mortality is almost equal in the normal BMI and BMI 25-30 subgroups. 


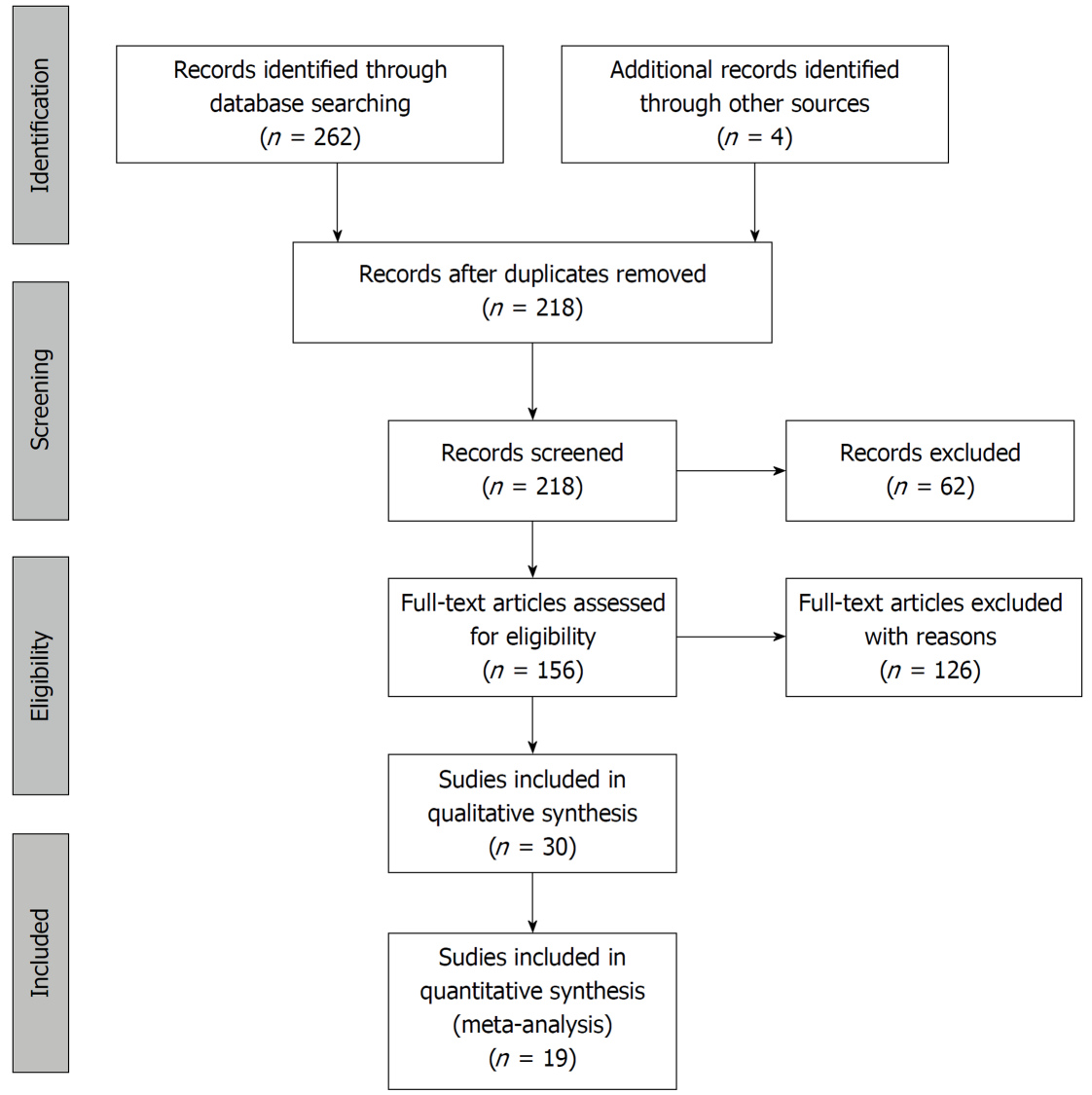

Figure 3 Flowchart of the study selection procedure.

\section{DISCUSSION}

The first meta-analysis ${ }^{[10]}$ on the topic of AP and BMI was published by Martínez et al in 2004, concluding that obesity significantly increases the risk of local or systemic complications in AP. Since then, three more meta-analyses have also confirmed the prognostic role of BMI in the disease, leading to even more specific results. The first meta-analysis was updated two years later by the same author ${ }^{[11]}$, confirming that obesity not only raises the risk of complications, but also increases the mortality in AP. In 2011, Wang et al ${ }^{[12]}$ highlighted that overweight (BMI > 25) also increases the incidence of SAP, while Hong et al ${ }^{[13]}$ drew attention to the prognostic role of body weight in AP development in their meta-analyses.

The main purpose of the present meta-analysis was to precisely evaluate the predictive value of BMI in AP by assessing what is already known and confirmed by evidence and to offer guidance on its use in clinical practice.

\section{Severity}

Seven of the included articles in this meta-analysis found a clear correlation between overweight or obesity and the development SAP. Two studies showed no significant relation between $\mathrm{BMI}$ and disease severity in $\mathrm{AP}^{[5,32]}$. Three articles ${ }^{[17-18,22]}$ analyzed the effect of BMI in comparison with other tools for measuring obesity. These studies stated that abdominal obesity (waist circumference), peripancreatic visceral adipose tissue and visceral fat-to-muscle ratio have a stronger correlation with SAP than BMI or body weight. We were also prepared to do an analysis of these data, but abdominal obesity is measured differently in each study ${ }^{[18,21-22,25,33]}$, making a meta-analysis inapplicable. One of the enrolled studies compared the accuracy of different scoring systems in predicting the severity of $\mathrm{AP}^{[19]}$, in which the addition of the obesity factor did not seem to improve the accuracy of the APACHE II scoring system. An interventional clinical trial ${ }^{[28]}$ was also conducted in this area, resulting in the successful prevention of severe AP in obese patients with the intravenous administration of octreotide.

Although previous studies have already confirmed the relation between BMI and the major endpoints of $\mathrm{AP}$, it is still not incorporated into the scoring systems that aim to predict disease outcome. A prospective study involving 186 consecutive patients 


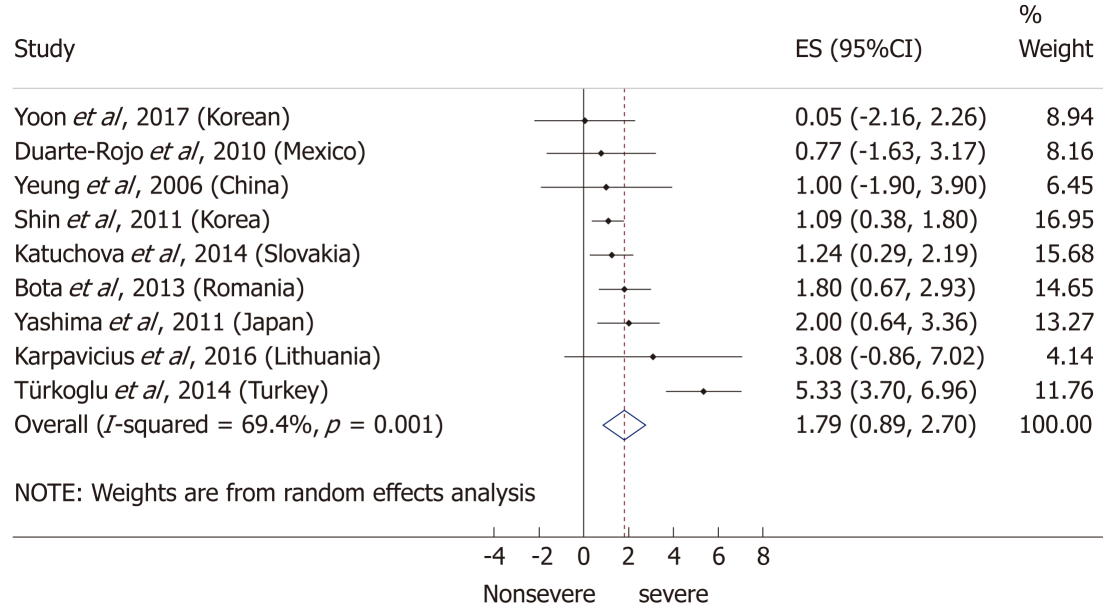

Figure 4 Forest plot of mean body-mass index in the non-severe and severe patient subgroups. Filled circles represent the mean difference derived from the studies analyzed. Horizontal bars represent $95 \% \mathrm{Cl}$. Empty rhombuses show the overall, combined mean difference (point estimation is the middle of the rhombus and Cls are the edges). $\mathrm{Cl}$ : Confidence interval.

published by Johnson et al ${ }^{[7]}$ in 2004 resulted in the improved prediction of severity in AP by adding the obesity factor to the APACHE II scoring system (Admission APACHE-O > 9: sensitivity $82 \%$, specificity $86 \%$, PPV $74 \%$, NPV $91 \%$ and accuracy 85\%; admission APACHE II > 9: sensitivity $68 \%$, specificity $84 \%$, PPV 71\%, NPV $81 \%$ and accuracy $80 \%$ ). Prevalence of complications increased among patients with a BMI 26-30 (score $=1$ ), while mortality rates were significantly higher among BMI $>30$ $($ score $=2)$ patients. Two years later, a prospective study of 101 patients ${ }^{[8]}$ also stated that obesity is an independent risk factor for severe AP and that the APACHE-O scoring system is not significantly better, but it has a similar predictive ability compared to APACHE II (Admission APACHE-O > 9: sensitivity 84\%, specificity 82\%, PPV 52\%, NPV 96\% and accuracy 83\%; admission APACHE II > 9: sensitivity $74 \%$, specificity $85 \%$, PPV 47\%, NPV 93\% and accuracy $80 \%$ ). In 2012, a cross-sectional retrospective study by Guzman et al ${ }^{[9]}$ added the BMI parameter to the Bedside Index of Severity in Acute Pancreatitis (BISAP) score and achieved higher diagnostic accuracy than the original scoring system (sensitivity 75\%, specificity $96.4 \%$, PPV $80 \%$, NPV $95.2 \%$ and accuracy $92.3 \%$ ).

\section{Mortality}

All the included articles found a correlation between BMI and mortality in AP. One study ${ }^{[31]}$ identified underweight as another independent risk factor for a fatal disease outcome, and our meta-analysis confirmed this. However, the number of patients was very low in this subgroup.

\section{Limitations}

Overweight and obesity are often accompanied by other chronic diseases and metabolic derangements such as hypertension, diabetes and hypertriglyceridemia. As we did not take demographic factors and comorbidities into consideration, we cannot conclude if $\mathrm{BMI}$ is an independent or associated risk factor in $\mathrm{AP}$, which is a limitation of this study.

\section{Strengths}

Our meta-analysis is much more comprehensive and detailed compared to the earlier ones. This work performs the first detailed analysis on all WHO BMI categories, by comparing the normal BMI subgroup to all other subgroups of BMI with regard to both severity and mortality in AP. Our subgroup analysis also investigated each BMI category, this way, we are now able to determine which BMI groups are most in danger of a severe or even fatal outcome in AP.

In conclusion, the findings of this meta-analysis demonstrated that a BMI above 25 increases the risk of severe $\mathrm{AP}$, but not mortality, while a BMI $>30$ raises the risk of both severity and mortality in AP. A BMI $<18.5$ carries an almost two times higher risk of mortality in AP. 


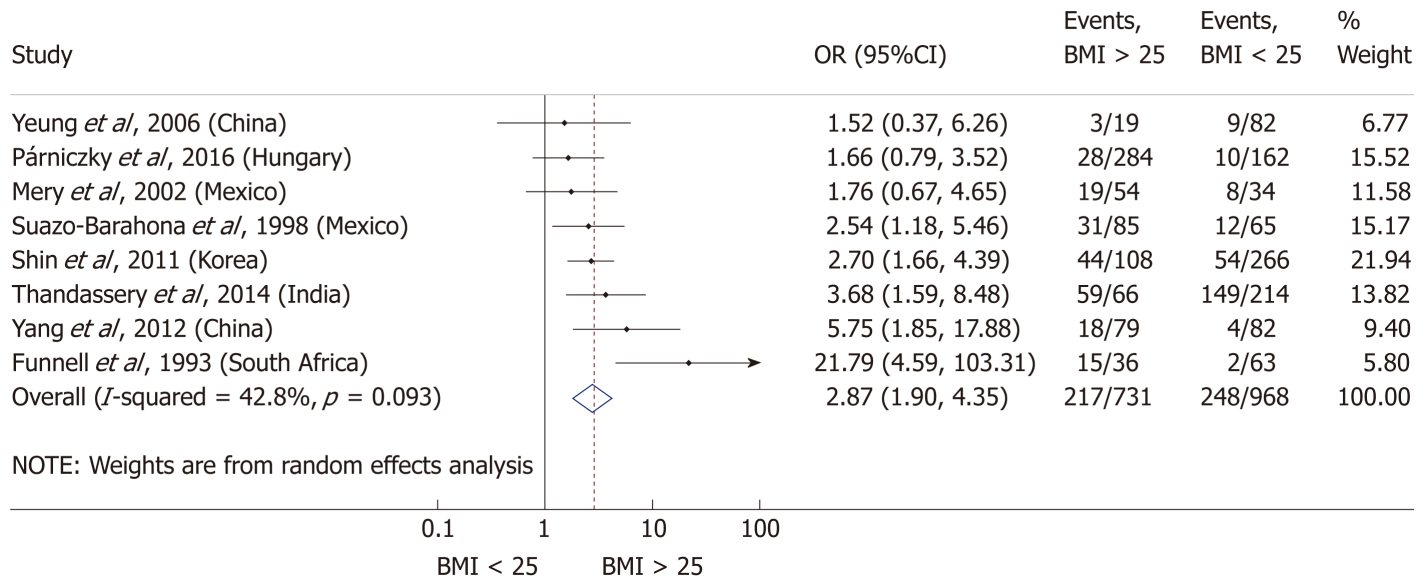

Figure 5 Forest plot of severe acute pancreatitis in the body-mass index $<25$ and body-mass index $>25$ subgroups. Filled circles represent the odds ratio derived from the studies analyzed. Horizontal bars represent $95 \% \mathrm{Cl}$. Empty rhombuses show the overall, combined effect (OR is the middle of the rhombus and $\mathrm{Cls}$ are the edges). BMl: Body-mass index; Cl: Confidence interval; OR: Odds ratio.

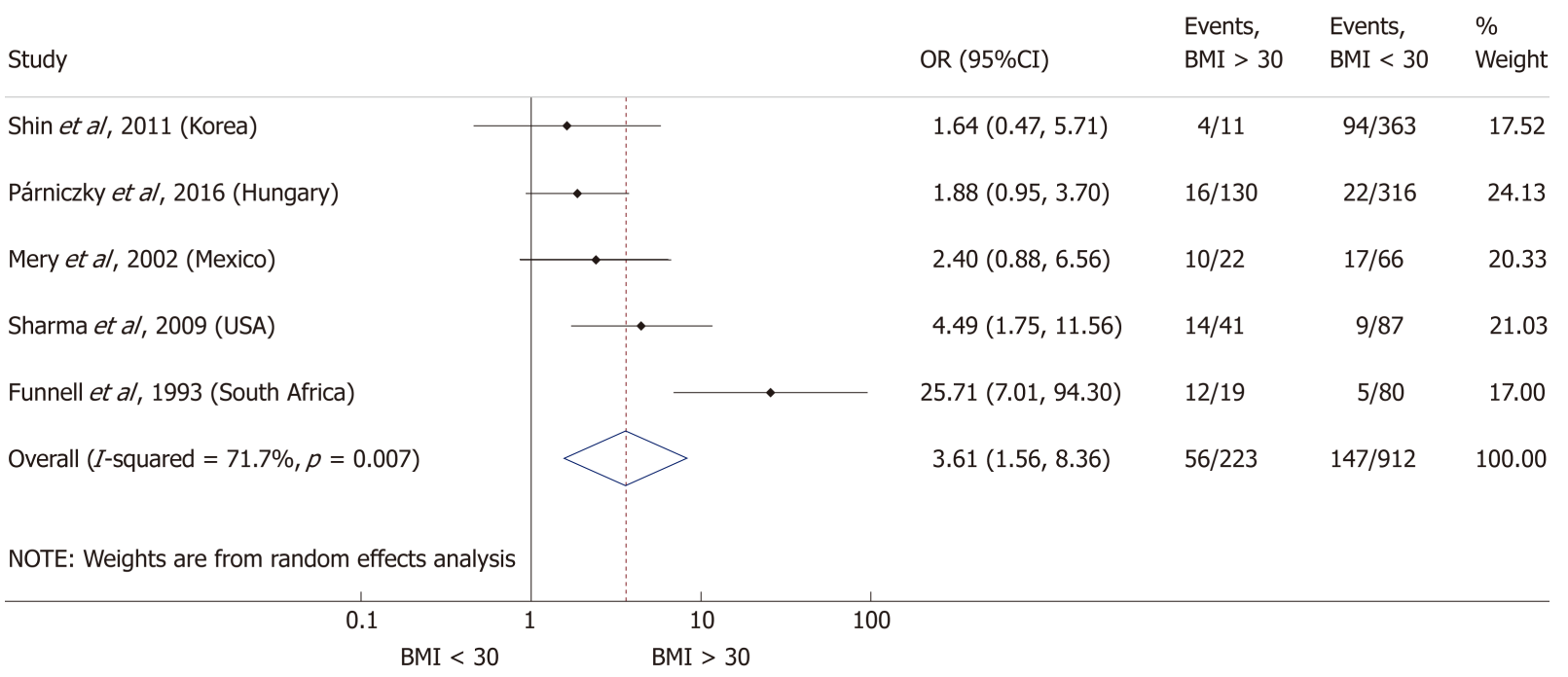

Figure 6 Forest plot of severe acute pancreatitis in the body-mass index $<\mathbf{3 0}$ and body-mass index $>\mathbf{3 0}$ subgroups. Filled circles represent the odds ratio derived from the studies analyzed. Horizontal bars represent $95 \% \mathrm{Cl}$. Empty rhombuses show the overall, combined effect (OR is the middle of the rhombus and $\mathrm{Cls}$ are the edges). BMl: Body-mass index; $\mathrm{Cl}$ : Confidence interval; OR: Odds ratio. 


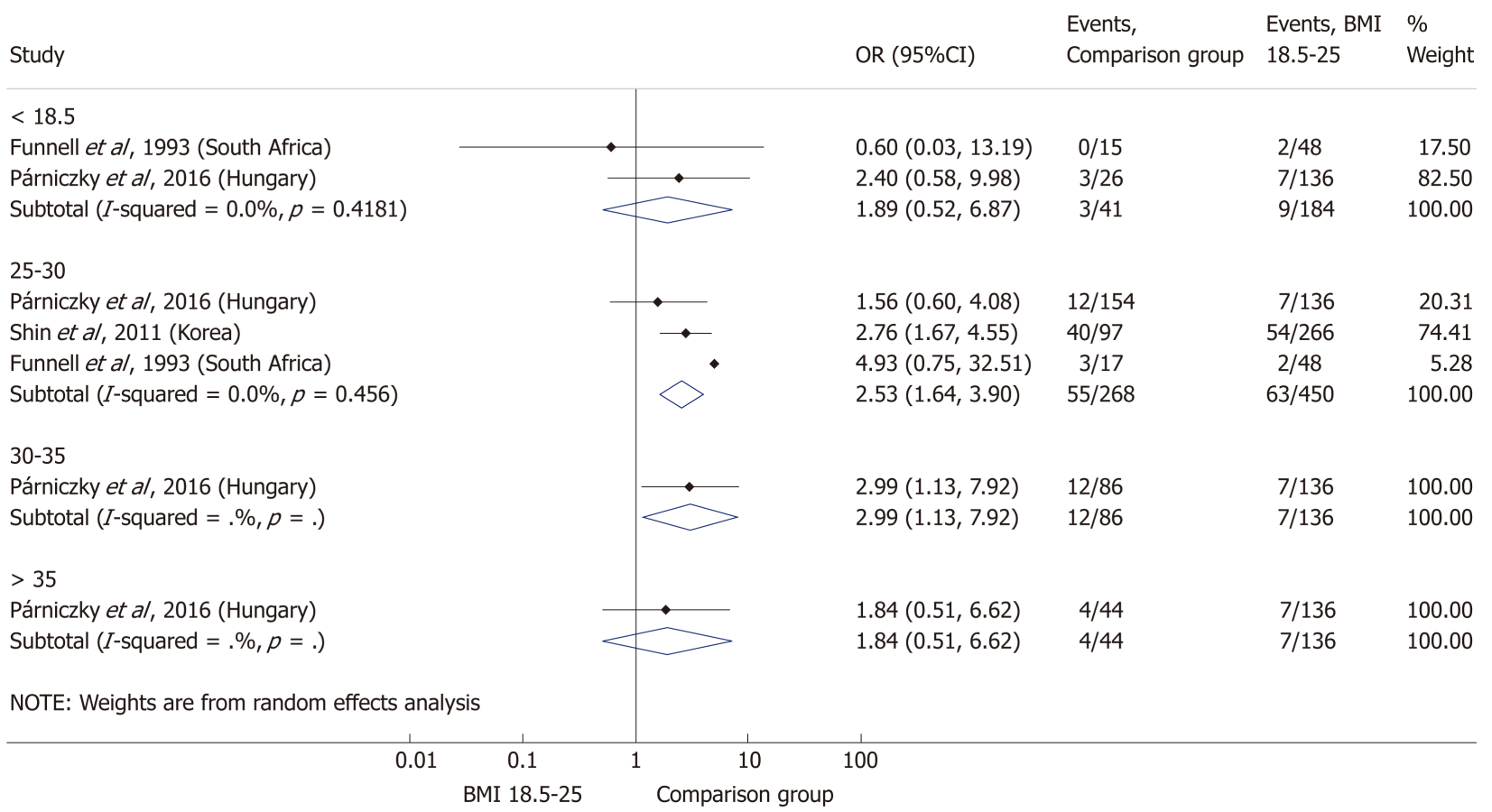

Figure 7 Forest plot of acute pancreatitis severity comparing the normal body-mass index group (body-mass index 18.5-25) to other body-mass index categories. Filled circles represent the odds ratio derived from the studies analyzed. Horizontal bars represent $95 \% \mathrm{Cl}$. Empty rhombuses show the overall, combined effect (OR is the middle of the rhombus and Cls are the edges). BMI: Body-mass index; Cl: Confidence interval; OR: Odds ratio.

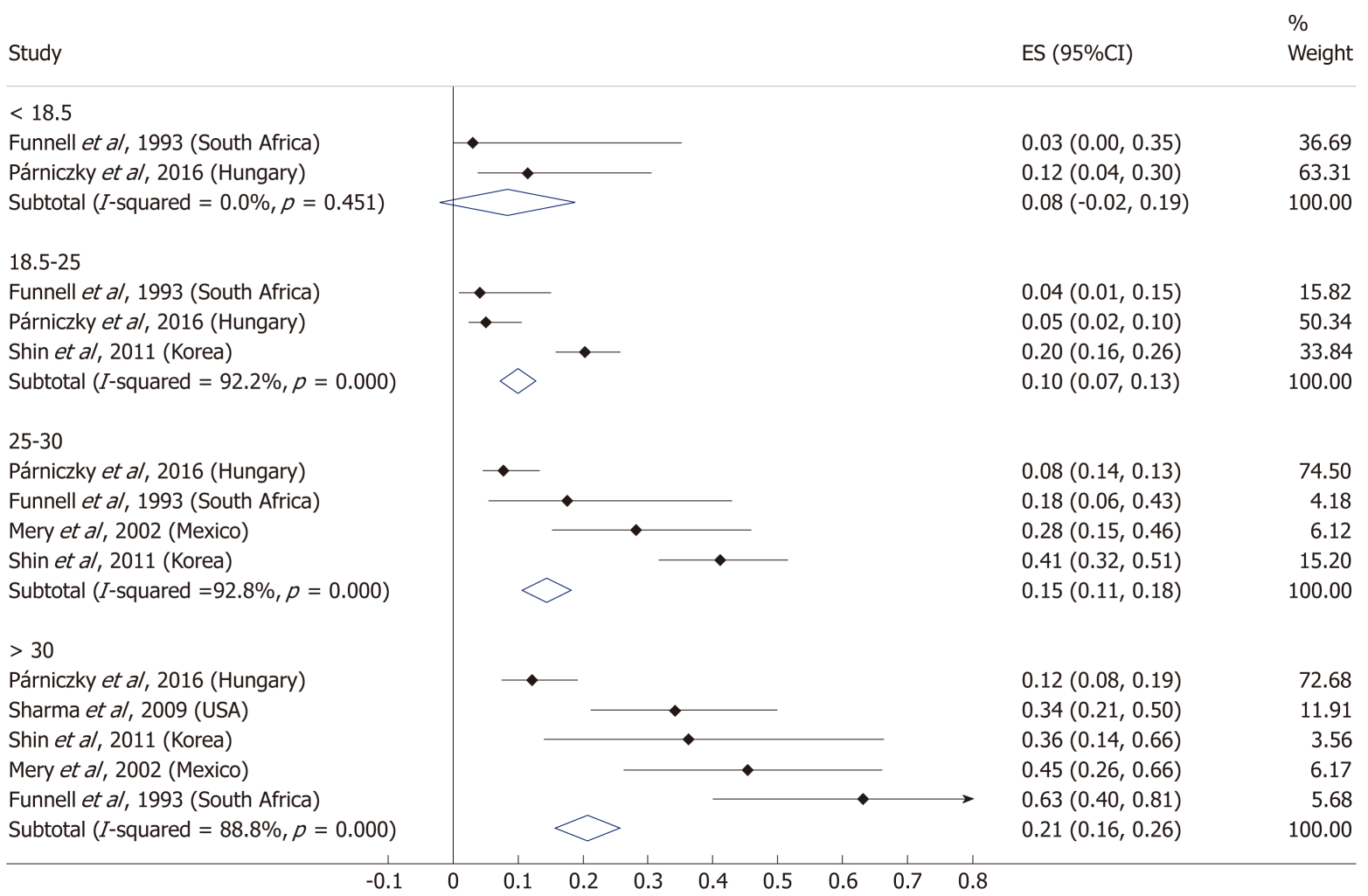

Figure 8 Subgroup analysis of body-mass index and acute pancreatitis severity displayed on forest plot. Filled circles represent the odds ratio derived from the studies analyzed. Horizontal bars represent $95 \% \mathrm{Cl}$. Empty rhombuses show the overall, combined effect (OR is the middle of the rhombus and Cls are the edges). Cl: Confidence interval. 


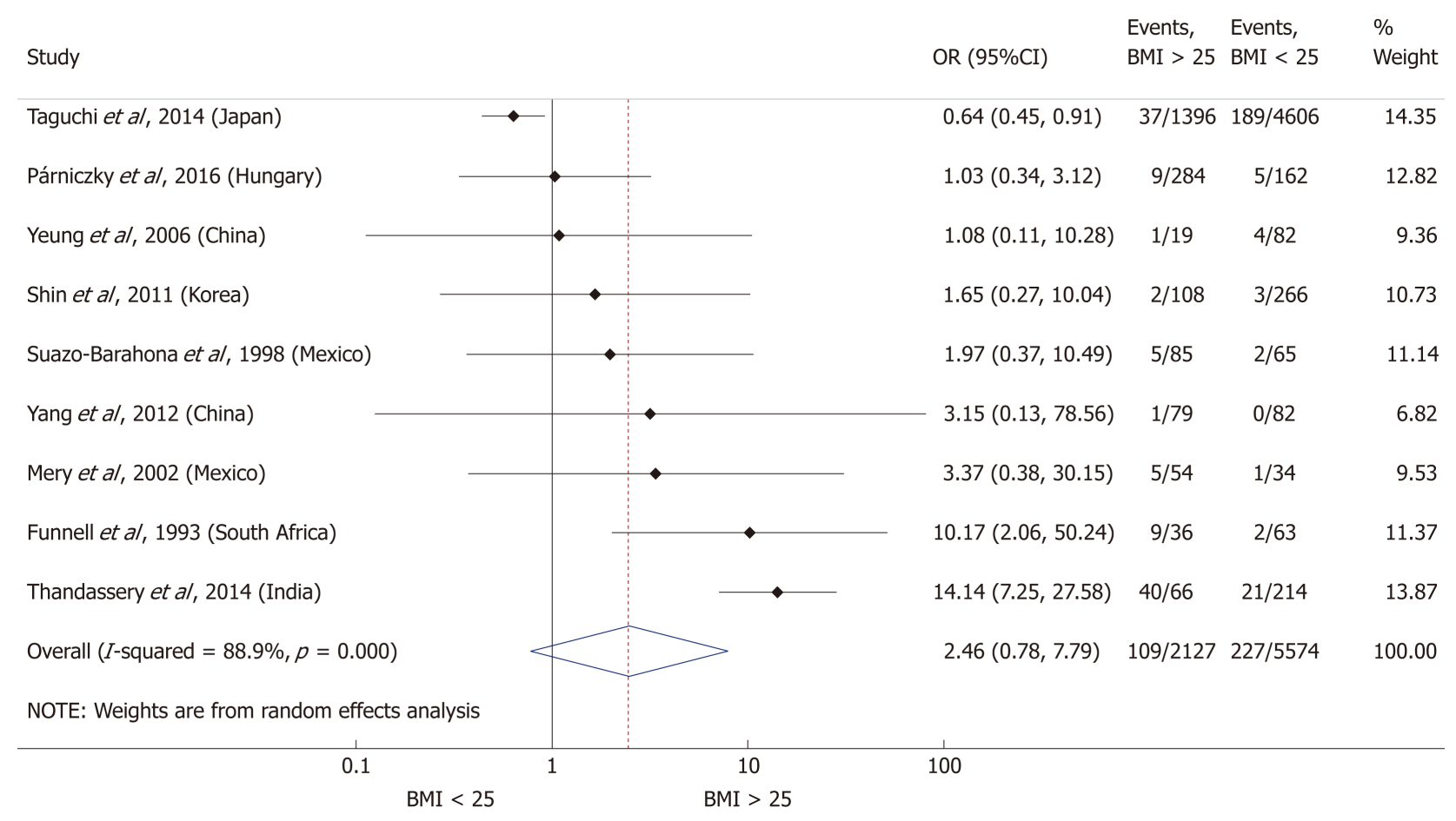

Figure 9 Forest plot of mortality comparing the body-mass index $<25$ and body-mass index $>25$ subgroups. Filled circles represent the odds ratio derived from the studies analyzed. Horizontal bars represent $95 \% \mathrm{Cl}$. Empty rhombuses show the overall, combined effect (OR is the middle of the rhombus and $\mathrm{Cls}$ are the edges). BMI: Body-mass index; Cl: Confidence interval; OR: Odds ratio.

Study

Taguchi et al, 2014 (Japan)

Mery et al, 2002 (Mexico)

Párniczky et al, 2016 (Hungary)

Shin et al, 2011 (Korea)

Funnell et al, 1993 (South Africa)

Papachristou et al, 2006 (USA)

Overall $(I$-squared $=62.7 \%, p=0.020)$

NOTE: Weights are from random effects analysis
OR $(95 \% C I)$

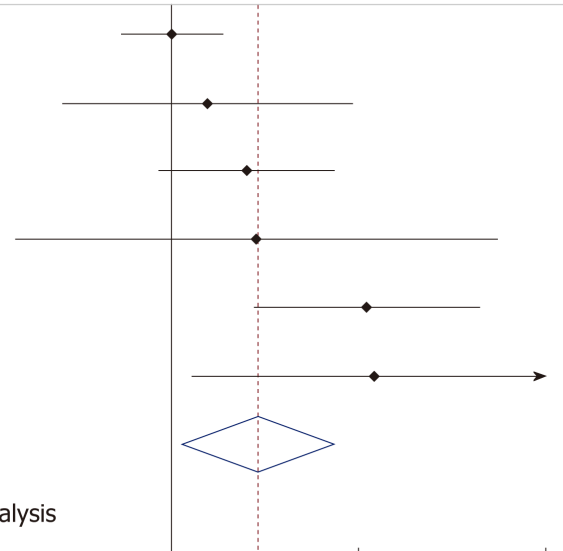

$1.01(0.54,1.87) \quad 11 / 290 \quad 215 / 5712 \quad 26.81$

$1.55(0.26,9.11) \quad 2 / 22 \quad 4 / 66 \quad 14.52$

$2.51(0.86,7.31) \quad 7 / 130 \quad 7 / 316 \quad 21.73$

$2.83(0.15,54.36) \quad 0 / 11 \quad 5 / 363 \quad 7.52$

$11.08(2.81,43.66) \quad 7 / 19 \quad 4 / 80 \quad 18.36$

$12.17(1.30,114.21) \quad 4 / 28 \quad 1 / 74 \quad 11.06$

$2.89(1.14,7.36) \quad 31 / 500 \quad 236 / 6611 \quad 100.00$

$\mathrm{BMI}<30$

$\mathrm{BMI}>30$

Figure 10 Forest plot of mortality comparing the body-mass index $<30$ and body-mass index $>30$ subgroups. Filled circles represent the odds ratio derived from the studies analyzed. Horizontal bars represent $95 \% \mathrm{Cl}$. Empty rhombuses show the overall, combined effect (OR is the middle of the rhombus and Cls are the edges). BMI: Body-mass index; Cl: Confidence interval; OR: Odds ratio. 


\begin{tabular}{|c|c|c|c|c|c|c|}
\hline Study & & & OR $(95 \% \mathrm{CI})$ & $\begin{array}{l}\text { Events, } \\
\text { Comparison group }\end{array}$ & $\begin{array}{l}\text { Events, BMI } \\
18.5-25\end{array}$ & $\begin{array}{l}\% \\
\text { Weight }\end{array}$ \\
\hline \multicolumn{7}{|l|}{$<18.5$} \\
\hline Funnell et al, 1993 (South Africa) & $\bullet$ & & $0.60(0.03,13.19)$ & $0 / 15$ & $2 / 48$ & 1.07 \\
\hline Párniczky et al, 2016 (Hungary) & 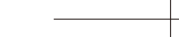 & . & $1.32(0.14,12.31)$ & $1 / 26$ & $4 / 136$ & 2.05 \\
\hline Taguchi et al, 2014 (Japan) & & $\rightarrow$ & $1.85(1.34,2.56)$ & $54 / 839$ & $135 / 3767$ & 96.88 \\
\hline Subtotal $(I$-squared $=0.0 \%, p=0.746)$ & & $\diamond$ & $1.82(1.321,2.50)$ & $55 / 880$ & $141 / 3951$ & 100.00 \\
\hline \multicolumn{7}{|l|}{$25-30$} \\
\hline Párniczky et al, 2016 (Hungary) & $\cdot$ & - & $0.43(0.08,2.41)$ & $2 / 154$ & $4 / 136$ & 11.18 \\
\hline Taguchi et al, 2014 (Japan) & $\rightarrow$ & & $0.65(0.42,0.99)$ & $26 / 1106$ & $135 / 3767$ & 70.54 \\
\hline Shin et al, 2011 (Korea) & & - & $1.85(0.30,11.22)$ & 2/97 & $3 / 266$ & 10.18 \\
\hline Funnell et al, 1993 (South Africa) & - & $\bullet$ & $3.07(0.40,23.70)$ & $2 / 17$ & $2 / 48$ & 8.10 \\
\hline Subtotal $(I$-squared $=15.3 \%, p=0.315)$ & & $>$ & $0.78(0.13,1.43)$ & $32 / 1374$ & $144 / 4217$ & 100.00 \\
\hline \multicolumn{7}{|l|}{$30-35$} \\
\hline Taguchi et al, 2014 (Japan) & $\longrightarrow$ & - & $0.88(0.41,1.91)$ & $7 / 220$ & $135 / 3767$ & 63.28 \\
\hline Párniczky et al, 2016 (Hungary) & 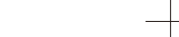 & 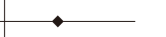 & $2.47(0.68,9.04)$ & $6 / 86$ & $4 / 136$ & 36.72 \\
\hline Subtotal $(I$-squared $=44.1 \%, p=0.181)$ & $<$ & & $1.29(0.49,3.41)$ & $13 / 306$ & $139 / 3903$ & 100.00 \\
\hline \multicolumn{7}{|l|}{$>35$} \\
\hline Párniczky et al, 2016 (Hungary) & - & & $0.77(0.08,7.05)$ & $1 / 44$ & $4 / 136$ & 17.56 \\
\hline Taguchi et al, 2014 (Japan) & - & $\cdot$ & $1.63(0.59,4.54)$ & $4 / 70$ & $135 / 3767$ & 82.44 \\
\hline Subtotal $(I$-squared $=0.0 \%, p=0.542)$ & $<$ & & $1.43(0.56,3.62)$ & $5 / 114$ & $139 / 3903$ & 100.00 \\
\hline \multicolumn{7}{|c|}{ NOTE: Weights are from random effects analysis } \\
\hline 0.01 & 0.1 & 10 & 100 & & & \\
\hline
\end{tabular}

Figure 11 Forest plot of mortality comparing the normal body-mass index group (body-mass index 18.5-25) to other body-mass index categories. Filled circles represent the odds ratio derived from the studies analyzed. Horizontal bars represent $95 \% \mathrm{Cl}$. Empty rhombuses show the overall, combined effect (OR is the middle of the rhombus and Cls are the edges). BMI: Body-mass index; Cl: Confidence interval; OR: Odds ratio.

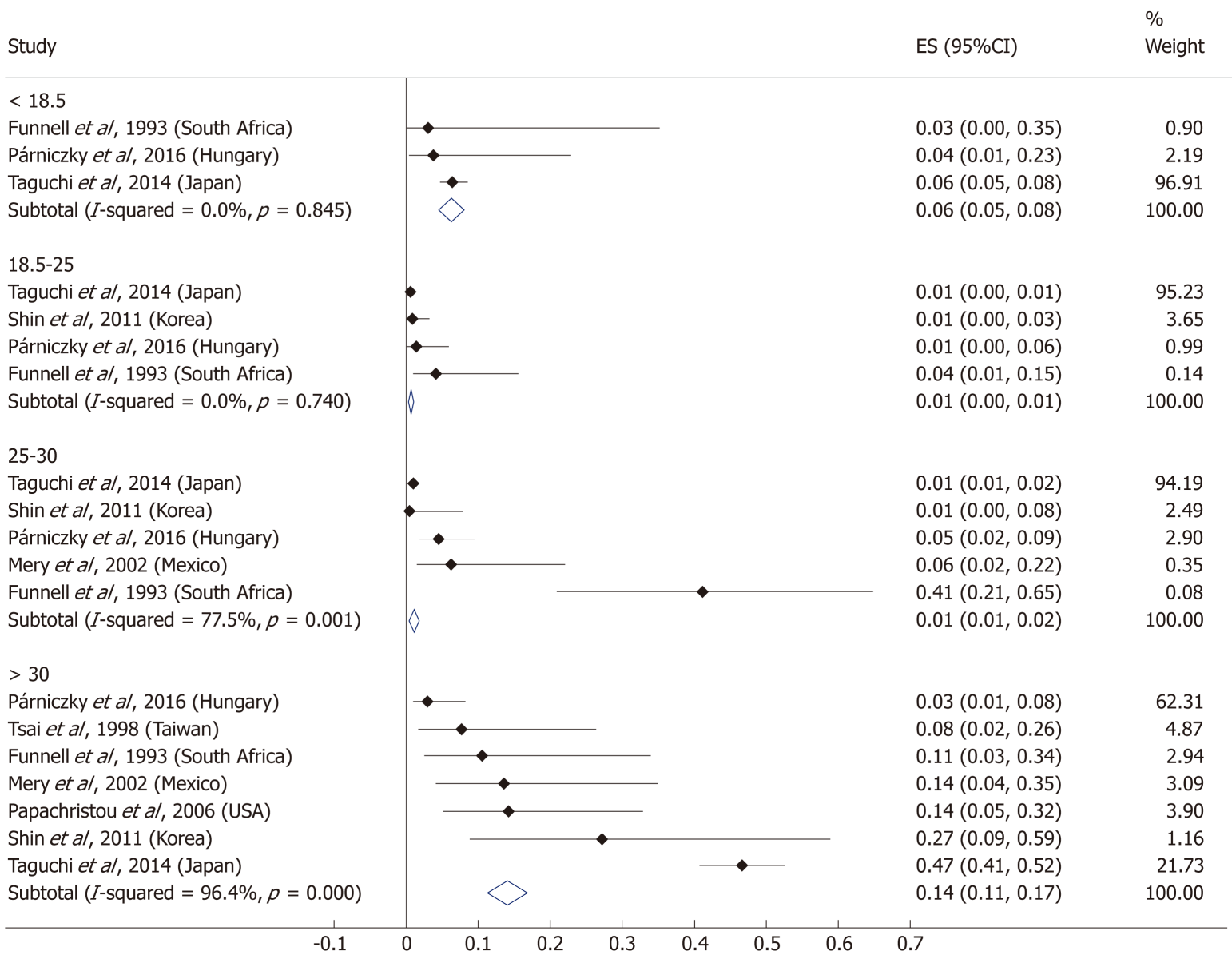


Figure 12 Subgroup analysis of body-mass index and acute pancreatitis mortality displayed on forest plot. Filled circles represent the odds ratio derived from the studies analyzed. Horizontal bars represent $95 \% \mathrm{Cl}$. Empty rhombuses show the overall, combined effect (OR is the middle of the rhombus and $\mathrm{Cls}$ are the edges). Cl: Confidence interval.

A

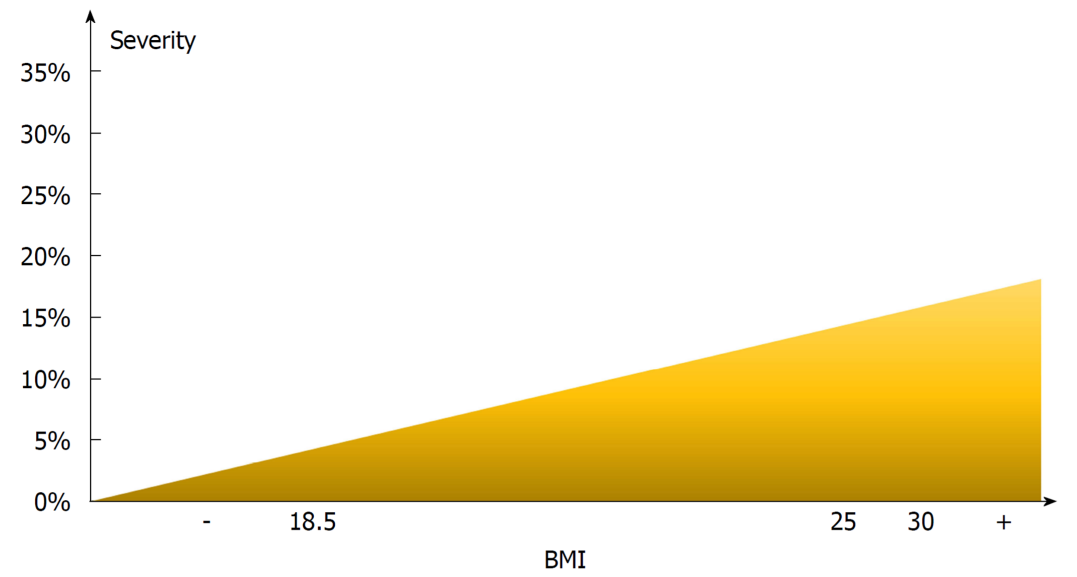

B

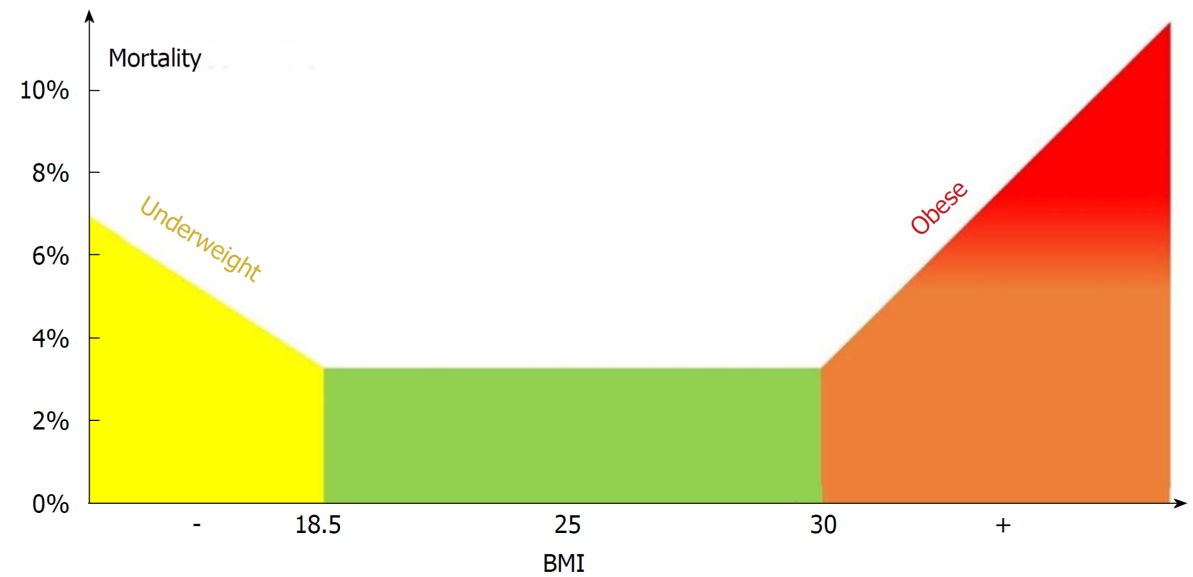

Figure 13 Model for the effect of body-mass index on severity (A) and mortality (B).

\section{ARTICLE HIGHLIGHTS}

\section{Research background}

The worldwide incidence of obesity is increasing and previous studies stated that it worsens the outcome of AP.

\section{Research motivation}

We wanted to provide detailed guidance on the clinical use of BMI in prognostic scoring.

\section{Research objectives}

To exactly identify which BMI subgroups are most in danger of a severe or even fatal disease outcome in AP.

\section{Research methods}

A systematic search was carried out in PubMed, Embase and Cochrane Library databases for studies investigating the effect of BMI on the outcome of AP. We used the PRISMA protocol, registered our project in PROSPERO and assessed the quality of the included articles by using a modified version of the Newcastle-Ottawa Scale. The statistical calculations were performed with Stata $11 \mathrm{SE}$, using the random effects model (DerSimonian-Laird method).

\section{Research results}

9997 patients with acute pancreatitis were included (19 articles) in this analysis. We found that AP patients with a BMI $>25$ have a significantly increased risk of SAP with an OR of 2.87 . A BMI $>30$ means a significantly increased risk of mortality $(\mathrm{OR}=2.89)$ while one with a $\mathrm{BMI}<18.5$ is 
also at a significantly higher risk of mortality compared to normal weight patients with an OR of 1.82

\section{Research conclusions}

The new findings of this study identified that a BMI above 25 increases the risk of severe AP, but not mortality, while a BMI $>30$ raises the risk of mortality. A BMI $<18.5$ carries an almost two times higher risk of mortality in AP. It is the first meta-analysis that performs a detailed analysis on all WHO BMI categories with regard to both primary endpoints of AP. This helps to determine which BMI groups are at the highest risk of severe or even fatal outcome in AP.

\section{Research perspectives}

Our results give the opportunity for researchers to prepare the guidelines and scoring systems more precisely.

\section{REFERENCES}

1 Bray GA, Heisel WE, Afshin A, Jensen MD, Dietz WH, Long M, Kushner RF, Daniels SR, Wadden TA Tsai AG, Hu FB, Jakicic JM, Ryan DH, Wolfe BM, Inge TH. The Science of Obesity Management: An Endocrine Society Scientific Statement. Endocr Rev 2018; 39: 79-132 [PMID: 29518206 DOI: 10.1210/er.2017-00253]

2 World Health Organization. Global Health Observatory data repository [cited 31 Aug 2018] Database: Global Health Observatory (GHO) data [Internet]. Available from: URL:

http://apps.who.int/gho/data/node.main.A897A?lang=en.

3 Withrow D, Alter DA. The economic burden of obesity worldwide: a systematic review of the direct costs of obesity. Obes Rev 2011; 12: 131-141 [PMID: 20122135 DOI: 10.1111/j.1467-789X.2009.00712.x]

4 Seidell JC, Flegal KM. Assessing obesity: classification and epidemiology. Br Med Bull 1997; 53: 238252 [PMID: 9246834]

5 Párniczky A, Kui B, Szentesi A, Balázs A, Szücs Á, Mosztbacher D, Czimmer J, Sarlós P, Bajor J, Gódi S, Vincze Á, Illés A, Szabó I, Pár G, Takács T, Czakó L, Szepes Z, Rakonczay Z, Izbéki F, Gervain J, Halász A, Novák J, Crai S, Hritz I, Góg C, Sümegi J, Golovics P, Varga M, Bod B, Hamvas J, VargaMüller M, Papp Z, Sahin-Tóth M, Hegyi P; Hungarian Pancreatic Study Group. Prospective, Multicentre, Nationwide Clinical Data from 600 Cases of Acute Pancreatitis. PLoS One 2016; 11: e0165309 [PMID: 27798670 DOI: 10.1371/journal.pone.0165309]

6 Working Group IAP/APA Acute Pancreatitis Guidelines. IAP/APA evidence-based guidelines for the management of acute pancreatitis. Pancreatology 2013; 13: e1-15 [PMID: 24054878 DOI: 10.1016/j.pan.2013.07.063]

7 Johnson CD, Toh SK, Campbell MJ. Combination of APACHE-II score and an obesity score (APACHEO) for the prediction of severe acute pancreatitis. Pancreatology 2004; 4: 1-6 [PMID: 14988652 DOI: 10.1159/000077021]

8 Papachristou GI, Papachristou DJ, Avula H, Slivka A, Whitcomb DC. Obesity increases the severity of acute pancreatitis: performance of APACHE-O score and correlation with the inflammatory response. Pancreatology 2006; 6: 279-285 [PMID: 16636600 DOI: 10.1159/000092689]

9 Guzmán Calderon E, Montes Teves P, Monge Salgado E. [Bisap-O: obesity included in score BISAP to improve prediction of severity in acute pancreatitis]. Rev Gastroenterol Peru 2012; 32: 251-256 [PMID: 23128944]

10 Martínez J, Sánchez-Payá J, Palazón JM, Suazo-Barahona J, Robles-Díaz G, Pérez-Mateo M. Is obesity a risk factor in acute pancreatitis? A meta-analysis. Pancreatology 2004; 4: $42-48$ [PMID: 14988657 DOI: 10.1159/000077025]

11 Martínez J, Johnson CD, Sánchez-Payá J, de Madaria E, Robles-Díaz G, Pérez-Mateo M. Obesity is a definitive risk factor of severity and mortality in acute pancreatitis: an updated meta-analysis. Pancreatology 2006; 6: 206-209 [PMID: 16549939 DOI: 10.1159/000092104]

12 Wang SQ, Li SJ, Feng QX, Feng XY, Xu L, Zhao QC. Overweight is an additional prognostic factor in acute pancreatitis: a meta-analysis. Pancreatology 2011; 11: $92-98$ [PMID: 21577040 DOI: 10.1159/000327688]

13 Hong S, Qiwen B, Ying J, Wei A, Chaoyang T. Body mass index and the risk and prognosis of acute pancreatitis: a meta-analysis. Eur J Gastroenterol Hepatol 2011; 23: 1136-1143 [PMID: 21904207 DOI: 10.1097/MEG.0b013e32834b0e0e]

14 Moher D, Liberati A, Tetzlaff J, Altman DG; PRISMA Group. Preferred reporting items for systematic reviews and meta-analyses: the PRISMA statement. BMJ 2009; 339: b2535 [PMID: 19622551 DOI: 10.1136/bmj.b2535]

15 Bradley EL. A clinically based classification system for acute pancreatitis. Summary of the International Symposium on Acute Pancreatitis, Atlanta, Ga, September 11 through 13, 1992. Arch Surg 1993; 128: 586-590 [PMID: 8489394]

16 Sarr MG, Banks PA, Bollen TL, Dervenis C, Gooszen HG, Johnson CD, Tsiotos GG, Vege SS. The new revised classification of acute pancreatitis 2012. Surg Clin North Am 2013; 93: 549-562 [PMID: 23632143 DOI: 10.1016/j.suc.2013.02.012]

17 Yoon SB, Choi MH, Lee IS, Lim CH, Kim JS, Cho YK, Park JM, Lee BI, Cho YS, Choi MG. Impact of body fat and muscle distribution on severity of acute pancreatitis. Pancreatology 2017; 17: 188-193 [PMID: 28190685 DOI: 10.1016/j.pan.2017.02.002]

18 Duarte-Rojo A, Sosa-Lozano LA, Saúl A, Herrera-Cáceres JO, Hernández-Cárdenas C, VázquezLamadrid J, Robles-Díaz G. Methods for measuring abdominal obesity in the prediction of severe acute pancreatitis, and their correlation with abdominal fat areas assessed by computed tomography. Aliment Pharmacol Ther 2010; 32: 244-253 [PMID: 20374222 DOI: 10.1111/j.1365-2036.2010.04321.x]

19 Yeung YP, Lam BY, Yip AW. APACHE system is better than Ranson system in the prediction of severity of acute pancreatitis. Hepatobiliary Pancreat Dis Int 2006; 5: 294-299 [PMID: 16698595]

20 Shin KY, Lee WS, Chung DW, Heo J, Jung MK, Tak WY, Kweon YO, Cho CM. Influence of obesity on the severity and clinical outcome of acute pancreatitis. Gut Liver 2011; 5: 335-339 [PMID: 21927663 DOI: 10.5009/gn1.2011.5.3.335] 
21 Katuchova J, Bober J, Harbulak P, Hudak A, Gajdzik T, Kalanin R, Radonak J. Obesity as a risk factor for severe acute pancreatitis patients. Wien Klin Wochenschr 2014; 126: 223-227 [PMID: 24522641 DOI: 10.1007/s00508-014-0507-7]

22 Yashima Y, Isayama H, Tsujino T, Nagano R, Yamamoto K, Mizuno S, Yagioka H, Kawakubo K, Sasaki T, Kogure H, Nakai Y, Hirano K, Sasahira N, Tada M, Kawabe T, Koike K, Omata M. A large volume of visceral adipose tissue leads to severe acute pancreatitis. J Gastroenterol 2011; 46: 1213-1218 [PMID: 21805069 DOI: 10.1007/s00535-011-0430-x]

23 Karpavicius A, Dambrauskas Z, Gradauskas A, Samuilis A, Zviniene K, Kupcinskas J, Brimas G, Meckovski A, Sileikis A, Strupas K. The clinical value of adipokines in predicting the severity and outcome of acute pancreatitis. BMC Gastroenterol 2016; 16: 99 [PMID: 27549125 DOI: 10.1186/s12876-016-0514-4]

24 Türkoğlu A, Böyük A, Tanrıverdi MH, Gündüz E, Dusak A, Kaplan İ, Gümüș M. The potential role of BMI, plasma leptin, nesfatin-1 and ghrelin levels in the early detection of pancreatic necrosis and severe acute pancreatitis: a prospective cohort study. Int J Surg 2014; 12: 1310-1313 [PMID: 25448651 DOI: 10.1016/j.ijsu.2014.10.040]

25 Mery CM, Rubio V, Duarte-Rojo A, Suazo-Barahona J, Peláez-Luna M, Milke P, Robles-Díaz G. Android fat distribution as predictor of severity in acute pancreatitis. Pancreatology 2002; 2: 543-549 [PMID: 12435867 DOI: 10.1159/000066099]

26 Suazo-Baráhona J, Carmona-Sánchez R, Robles-Díaz G, Milke-García P, Vargas-Vorácková F, UscangaDomínguez L, Peláez-Luna M. Obesity: a risk factor for severe acute biliary and alcoholic pancreatitis. $A m$ J Gastroenterol 1998; 93: 1324-1328 [PMID: 9707059 DOI: 10.1111/j.1572-0241.1998.442_1.x]

27 Thandassery RB, Appasani S, Yadav TD, Dutta U, Indrajit A, Singh K, Kochhar R. Implementation of the Asia-Pacific guidelines of obesity classification on the APACHE-O scoring system and its role in the prediction of outcomes of acute pancreatitis: a study from India. Dig Dis Sci 2014; 59: 1316-1321 [PMID: 24374646 DOI: 10.1007/s10620-013-3000-7]

28 Yang F, Wu H, Li Y, Li Z, Wang C, Yang J, Hu B, Huang Z, Ji R, Zhan X, Xie H, Wang L, Zhang M, Tang C. Prevention of severe acute pancreatitis with octreotide in obese patients: a prospective multicenter randomized controlled trial. Pancreas 2012; 41: 1206-1212 [PMID: 23086244 DOI: 10.1097/MPA.0b013e3182523bdf]

29 Funnell IC, Bornman PC, Weakley SP, Terblanche J, Marks IN. Obesity: an important prognostic factor in acute pancreatitis. Br J Surg 1993; 80: 484-486 [PMID: 8495317]

30 Sharma A, Muddana V, Lamb J, Greer J, Papachristou GI, Whitcomb DC. Low serum adiponectin levels are associated with systemic organ failure in acute pancreatitis. Pancreas 2009; 38: 907-912 [PMID: 19696691 DOI: 10.1097/MPA.0b013e3181b65bbe]

31 Taguchi M, Kubo T, Yamamoto M, Muramatsu K, Yasunaga H, Horiguchi H, Fujimori K, Matsuda S, Fushimi K, Harada M. Body mass index influences the outcome of acute pancreatitis: an analysis based on the Japanese administrative database. Pancreas 2014; 43: 863-866 [PMID: 24786667 DOI: 10.1097/MPA.0000000000000137]

32 Bota S, Sporea I, Sirli R, Popescu A, Strain M, Focsa M, Danila M, Chisevescu D. Predictive factors for severe evolution in acute pancreatitis and a new score for predicting a severe outcome. Ann Gastroenterol 2013; 26: 156-162 [PMID: 24714801]

33 Sadr-Azodi O, Orsini N, Andrén-Sandberg Å, Wolk A. Abdominal and total adiposity and the risk of acute pancreatitis: a population-based prospective cohort study. Am J Gastroenterol 2013; 108: 133-139 [PMID: 23147519 DOI: 10.1038/ajg.2012.381]

34 Tsai CJ. Is obesity a significant prognostic factor in acute pancreatitis? Dig Dis Sci 1998; 43: 2251-2254 [PMID: 9790461]

P- Reviewer: Gonoi W, Löhr JM

S- Editor: Gong ZM L- Editor: A E- Editor: Yin SY 


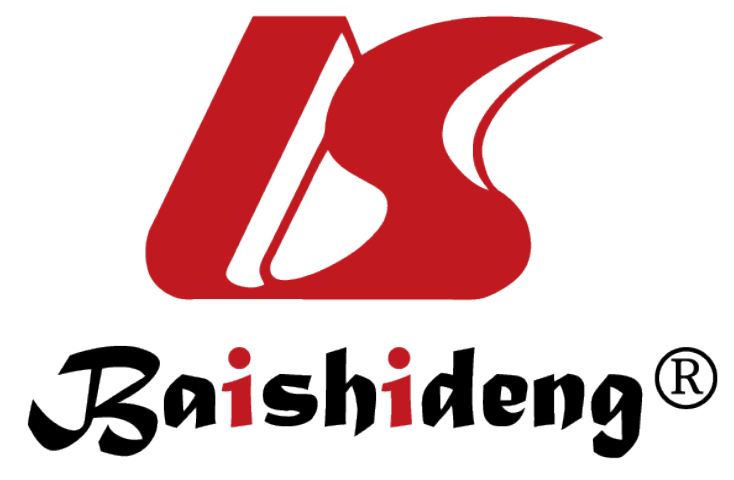

Published By Baishideng Publishing Group Inc 7901 Stoneridge Drive, Suite 501, Pleasanton, CA 94588, USA Telephone: +1-925-2238242

Fax: +1-925-2238243

E-mail: bpgoffice@wignet.com

Help Desk:http://www.f6publishing.com/helpdesk

http://www.wjgnet.com

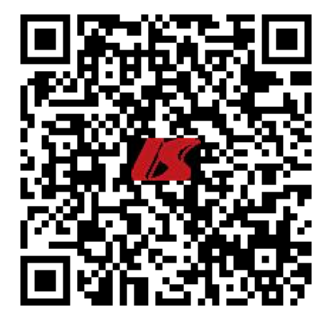

